\title{
Inter-institutional Training of Biodiversity Informatics Specialists
}

\author{
Robert D. Montoya $\ddagger$ \\ ‡ Indiana University Bloomington, Bloomington, Indiana, United States of America
}

Corresponding author: Robert D. Montoya (montoya@indiana.edu)

Received: 10 Jun 2018| Published: 17 Jul 2018

Citation: Montoya R (2018) Inter-institutional Training of Biodiversity Informatics Specialists. Biodiversity Information Science and Standards 2: e27339. https://doi.org/10.3897/biss.2.27339

\begin{abstract}
This presentation will outline the untapped potential of Information and Library Science (ILS) programs as an integral space for the long-term training and support of biodiversity informatics work. It will also outline the specific proposed steps taken at Indiana University, Bloomington (IU), to provide long-term, systematized training of students focused on information work within this broad domain.
\end{abstract}

As a discipline, ILS has long been preoccupied with the organization, description, curation, and access to a wide variety of information and data sources. ILS curriculum necessarily emphasizes a broad range of information topics given that many different kinds of institutions require these particular skillsets. Typical ILS curriculums focus on topics such as, knowledge organization, metadata, ontologies, database design, scholarly communication, intellectual property, information ethics, interface design, data analytics, online publishing, museum studies, data curation, and collection management/ administration. Given this broad range of training, students graduating from ILS programs are perfectly situated to support biodiversity informatics broadly conceived, especially as it relates to the standardization and normalization of data sources across geographically and temporally distributed locations and sources within specific institutional environments.

Yet, despite the overlaps between ILS departments, biodiversity informatics, and museum environments, no ILS program has officially taken steps to support this intersectional space. Using concrete examples, this talk will show how the ILS program at IU is building 
on top of already-existing capacities to more robustly support biodiversity work. The proposed way forward is a tightly integrated approach to biodiversity informatics that integrates theoretical experience and technical training with hands-on internships in museum and biodiversity environments. Through close partnerships with on-campus institutes, such as the Indiana Geological \& Water Survey and the Center for Biological Research Collections, as well as larger, external institutions such as the Smithsonian National Museum of Natural History, students will be provided intense fieldwork experience in data management and standards-driven work specific to the museum and biodiversity world. A tiered approach to this training will be suggested, as this kind of training should proceed at both the professional level (for example, master's level work), as well as more advanced levels focused on more research-driven activity (such as postdoctoral work).

Part of this new approach to biodiversity informatics training requires the rearticulation of ILS courses, as well as the addition of new courses that can provide domain-specific knowledge. This presentation, then, will outline a proposed curriculum to support this kind of collaborative training and work. A distributed training structure will be suggested, utilizing expertise from across the globe. In addition, it will show how a more project- and field workcentric approach to ILS education can more quickly and deeply train students to enter the quickly changing field.

Part of the difficulty with training biodiversity informatics specialists is that building such programs from the ground up is often costly and requires the building of new workflows and practices. An integrated approach, such as that proposed in this presentation, however, will leverage the respective strengths of ILS program and museum environments in ways that are sustainable and resilient for the long term. The goal here is for institutions to support each other in ways that strengthen their core missions, as well as push the discipline forward in systematic and unique ways.

\section{Keywords}

biodiversity informatics, Information and Library Science, museum informatics, training and education

\section{Presenting author}

Robert D. Montoya

\section{Presented at}

Plenary at Joint Meeting of SPNHC/TDWG 2018: Biodiversity: Global Outlook - Local Implementation 